\title{
Forragem de milho hidropônico produzida com diferentes substratos ${ }^{1}$
}

\section{José Elivalto Guimarães Campêlo ${ }^{2}$, José Crisóstomo Gomes de Oliveira ${ }^{2}$, André da Silva Rocha $^{3}$, José Francisco de Carvalho ${ }^{3}$, Geyson Coutinho Moura ${ }^{3}$, Maria Elizabete de Oliveira ${ }^{2}$, José Algaci Lopes da Silva ${ }^{2}$, José Wilson da Silva Moura ${ }^{2}$, Valter Marchão Costa ${ }^{4}$, Lindomar de Morais Uchoa 4}

\footnotetext{
${ }^{1}$ Pesquisa com recursos da UFPI. Campus da Socopo S/N - CEP: 64.055-449 - Teresina, PI. Fone: (86) 3251-5750.

2 Centro de Ciências Agrárias - UFPI.

3 Iniciação Científica Voluntária do curso de Agronomia - CCA/UFPI.

4 Técnico do DZO/CCA/UFPI.
}

RESUMO - Esta pesquisa foi realizada visando avaliar a qualidade do volumoso produzido com a técnica de hidroponia. Como substratos, utilizaram-se casca de arroz e capim-elefante picado cultivado sobre lona plástica, com densidade de $2,5 \mathrm{~kg}$ de grãos $/ \mathrm{m}^{2}$. Os dados foram analisados em delineamento inteiramente casualizado, com sete repetições, representadas por canteiros de $0,5 \times 0,5 \mathrm{~m}$ de área útil. A fertiirrigação foi usada do $3 \underline{0}$ ao 14 o dia após a semeadura, quando foi realizada a colheita para determinação da produtividade da forragem natural $/ \mathrm{m}^{2}$, da porcentagem de MS total e dos teores de PB, FDN, FDA e cinzas. Essas características foram determinadas em amostras da forragem completa, do substrato + raízes e em amostras apenas das plantas. O uso de casca de arroz como substrato resultou em maior produção de MS, FDN, FDA e cinzas. O capim-elefante destacoutse pelo maior teor de PB, mesmo que com baixo teor de MS. A PB apresentou relação inversa com MS, FDN, FDA e cinzas.

Palavras-chave: alimento alternativo, FDN, FDA, MS, PB, ruminantes

\section{Hydroponic corn forage produced on different substrates}

\begin{abstract}
This research was carried out to evaluate the quality of the roughage produced by hydroponics. Rice hulls and chopped elephantgrass were used as substrates for corn cultivation, put on plastic canvas. Corn seeding density was $2.5 \mathrm{~kg}$ of seed $/ \mathrm{m}^{2}$. A randomized experimental design was used, with seven replications. Plot utile area measured $0.5 \mathrm{~m} \times 0.5 \mathrm{~m}$. Fertiirrigation was used from the $3^{\text {rd }}$ to the $14^{\text {th }}$ day after seeding. Harvest occurred at the $14^{\text {th }}$ day and fresh forage productivity was determined. Three types of samples were taken: complete forage (shoot + root + substratum), substratum + roots, and shoot only. The following response variables were determined: DM concentration, CP, NDF, ADF, and ash. The rice hulls substratum resulted in higher DM production, NDF, ADF and ash concentration, while the chopped elephantgrass promoted greater CP concentration, although with low DM concentration. The CP presented inverse relationship with DM concentration and its components: NDF, ADF and ash.
\end{abstract}

Key Words: ADF, alternative food, DM, CP, NDF, ruminant

\section{Introdução}

O desenvolvimento de tecnologia capaz de amenizar os efeitos da redução da quantidade e qualidade das forragens durante a estação seca em regiões semi-áridas tem sido necessário na produção animal. No Nordeste, a qualidade e quantidade da forragem disponível nesse período do ano constituem um dos fatores responsáveis pela caracterização da atividade de muitos criadores na região, como pecuária de subsistência. Esse fato tem prevalecido ao longo dos anos demonstrando a importância de alternativas de convívio com a seca. A busca de resultados visando à melhoria da qualidade de vida do homem do campo tem sido contínua, devendo ser incluído também o bem-estar animal, uma cobrança atual do ponto de vista ético.

Nem todos os criadores da região fornecem no sistema de produção animal a pasto alimento adicional, como palma forrageira, feno e silagem, durante a estação seca, com vistas a manter níveis adequados de crescimento dos animais. O objetivo de muitos desses criadores, nas condições de criação existentes, é buscar formas de convivência com a seca, garantindo a mantença dos animais e evitando que venham a morrer de fome. 
Nesse cenário, pesquisadores têm trabalhado comduas situações aparentemente distintas, de modo que determinada tecnologia parece não ser adequada para todo o Nordeste: na primeira situação, estudiosos defendemestratégias para crescimento e ganho de peso na época seca do ano, como Souza \& Espíndola (1999), cujos resultados parecem mais recomendados para localidades de climas mais favoráveis e para propriedades mais tecnicamente equipadas; na se gunda, incluem-se aqueles que consideram que, na época seca, é mais importante a mantença dos animais.

No entanto, sob quaisquer dessas perspectivas, a pecuária da região perde competitividade e, como parece impossível mantê-la dependente do crescimento natural das pastagens, a alimentação animal torna-se prioridade no sistema de produção, face às relações de custos dos insumos (Reis et al., 2001). As sim, estudam-se opções de alimentação para os animais que resultem em qualidade de vida ao homem, obedecendo, no entanto, as particularidades regionais. Com essa finalidade, destaca-se o uso de pastagens cultivadas, de fenação, de silagem de produtos como milho, sorgo e cana-de-açúcar e de amonização de subprodutos da agricultura.

A utilização de alimentos concentrados é economicamente inadequada em muitos casos (Souza \& Espíndola, 1999). Segundo esses autores, o uso de feno de leguminosas é uma alternativa de complementação alimentar razoável, cuja produção está ao alcance, inclusive, do pequeno produtor. Segundo Reis et al. (2001), o uso do milho na alimentação animal é prejudicado por problemas como o ataque de insetos e de roedores causadores de desperdícios de grãos sob armazenamento inadequado, fatores que justificam o uso de silagem do milho ainda úmido. Outras opções para alimentação na região são a faveira de bolota (Parkia platicephala, Benth), a palma forrageira (Opuntia ficusindica Mipp) e os restos de culturas.

$\mathrm{Na}$ produção animal, os ruminantes são importantes especificamente pelo fato de aproveitarem subprodutos e resíduos agrícolas (Souza Gesualdi et al., 2001), implicando redução de custos na alimentação. Entretanto, a maioria desses produtos possui elevado teor de componentes indigestíveis como lignina e sílica, além de baixos valores de nitrogênio, minerais e energia, de modo que sua utilização depende de estratégias de enriquecimento, como a amonização, para torná-los fonte alternativa de alimento aos animais (Paiva et al., 1995).

A eficiência de amonização de volumoso de baixa qualidade tem merecido atenção da pesquisa, pois permite a melhora da qualidade do volumoso, elevando o teor de PB e reduzindo os níveis de FDN (Pires et al., 1991; Teixeira, 1990; Sarmento et al., 1999; Souza Gesualdi et al., 2001).
A produção de forragens por hidroponia constitui alternativa para o uso em pequenas e médias propriedades com dificuldades para manter a produção de volumosos de forma regular ao longo do ano (Amorim et al., 2000). Entre as vantagens desse volumoso em relação à silagem ou feno, destacam-se o ciclo rápido para produção contínua, o desenvolvimento sob quaisquer condições climáticas e a alta produtividade por área (Oliveira, 1998). Por outro lado, por ser uma inovação tecnológica, mesmo que simples, carece de informações sobre a qualidade de seus produtos, embora já esteja em uso por produtores da região, que recorrem à sua produção como opção de complementação ao programa alimentar quando a forragem disponível não é suficiente para todo o período seco.

Nesta pesquisa, objetivou-se avaliar os teores de MS, $\mathrm{PB}, \mathrm{FDN}, \mathrm{FDA}$ e cinzas do volumoso produzido com milho hidropônico cultivado em substrato de capim-elefante picado ou em casca de arroz.

\section{Materiais e Métodos}

$\mathrm{O}$ experimento foi realizado nos meses de outubro e novembro de 2002, com instalação dos canteiros no Departamento de Zootecnia (CCA/UFPI), em Teresina, Piauí. A temperatura média do ar no período variou de 29,7 a $31,8^{\circ} \mathrm{C}$ no mês de outubro e de 30,2 a $31,8^{\circ} \mathrm{C}$ em novembro. A umidade relativa média do ar oscilou entre 38 e $54 \%$ no mês de outubro e entre 42 e $61 \%$ em novembro.

O cultivo e a colheita foram realizados conforme método proposto por Oliveira (1998), que consiste no plantio do milho em sistema de hidroponia em canteiros preparados com os substratos e uso de fertiirrigação. Para cada substrato, utilizou-se o plantio diário de uma parcela durante o período de 15 dias, sendo a colheita realizada aos 15 dias do plantio e, conseqüentemente, por igual período de tempo.

Os canteiros, com área útil de $0,5 \times 0,5 \mathrm{~m}$ e espaçados a 0,5 m entre linhas, foram distribuídos de forma aleatória na área, em cima de lona preta de polietileno (15 micras) disposta sobre piso de concreto plano. Os canteiros foram preparados e irrigados com água 24 horas antes do plantio. As sementes de milho de cada tratamento foram pesadas e colocadas em baldes, sendo imersas em água por 24 horas para prégerminação. Para ambos os substratos estudados (casca de arroz e o capim-elefante picado e desidratado ao sol), a densidade de plantio foi de $2,5 \mathrm{~kg} / \mathrm{m}^{2}$, com as sementes dispostas sobre uma camada de substrato de $4 \mathrm{~cm}$ de espessura coberta por outra de $2 \mathrm{~cm}$.

Utilizou-se solução nutritiva recomendada para produção de forragem hidropônica de milho disponível no mercado de Teresina, Piauí, preparada segundo recomen- 
dação do fabricante, utilizando-se $2 \mathrm{~g}$ de um "composto de macronutrientes" (340 g de fosfato monoamônia, $2.080 \mathrm{~g}$ de nitrato de cálcio e $1.100 \mathrm{~g}$ de nitrato de potássio) e $2 \mathrm{~mL}$ de uma "solução de micronutrientes" (492 g de sulfato de magnésio, 0,48 $\mathrm{g}$ de sulfato de cobre, $12,5 \mathrm{~g}$ de sulfato de manganês, 1,2 g de sulfato de zinco, 6,2 g de ácido bórico, $0,02 \mathrm{~g}$ de molibidato de amônio e $15 \mathrm{~g}$ de quelato de ferro), ambos os compostos diluídos em $10 \mathrm{~L}$ de água.

Durante os três primeiros dias após o plantio, a irrigação foi realizada apenas com água limpa $\left(6 \mathrm{~L} / \mathrm{m}^{2} / \mathrm{dia}\right.$ em duas vezes). Quando iniciada a germinação, procedeu-se à fertiirrigação da seguinte forma: às 7 e $14 \mathrm{~h}$ - regas com $2 \mathrm{~L}$ da solução nutritiva por $\mathrm{m}^{2}$ de canteiro; às $11 \mathrm{e} 17 \mathrm{~h}$ - regas com $2 \mathrm{~L}$ de água limpa. Esse procedimento foi repetido durante 11 dias, sendo suspenso o uso da solução nutritiva um dia antes da colheita, para remoção de sais da forragem.

O delineamento utilizado foi o inteiramente casualizado, considerando repetições as colheitas realizadas do $5 \underline{0}$ ao 11으 dia, em um total de sete repetições por substrato. As demais colheitas foram consideradas bordadura.

A colheita foi feita pela manhã do 15ํ dia após a semeadura, sempre antes da irrigação diária, sendo colhida uma repetição por dia para cada substrato. No ato da colheita, determinou-se a produção de volumoso/m² por meio da pesagem, em balança com capacidade para $200 \mathrm{~kg}$, de toda a forragem produzida na parcela. Deste material, retiraram-se as amostras, que foram acondicionadas em sacos de papel e analisadas no Laboratório de Nutrição Animal do CCA/UFPI.

Para determinação da MS e da composição da forragem produzida, utilizou-se o método proposto por Silva (1998). Nas análises, foram determinados a porcentagem de MS total e os teores de PB, FDN, FDA e cinzas.

Avaliou-se a influência do substrato sobre as características estudadas, considerando-se as amostras colhidas em três situações distintas e analisadas separadamente, conforme a seguir: 1) forragem completa - substrato + plantas de milho; 2) substrato + raízes; e 3) parte aérea das plantas de milho. Os componentes de variância e as médias dos substratos comparadas pelo teste Tukey $(\mathrm{P}<0,01)$, para cada situação, foram obtidos por meio do SAEG versão 8.0 (Euclydes, 1983).

\section{Resultados e Discussão}

As médias e os coeficientes de variação obtidos para forragem natural, MS total e para os teores de PB, FDN, FDA e cinzas são apresentados na Tabela 1 , simultaneamente para forragem completa, substrato + raízes e parte aérea das plantas de milho. A produção de forragem natural $/ \mathrm{m}^{2}$ foi de
21,6 e $24,5 \mathrm{~kg}$, respectivamente, para o plantio em substrato de capim-elefante e casca de arroz.

A quantidade de forragem natural e de MS produzida com milho hidropônico por área foi influenciada pelo tipo de substrato. Utilizando-se a casca de arroz, o teor de MS foi superior ao capim-elefante, de maior teor de umidade $(7,16 \mathrm{vs}$ $3,92 \mathrm{~kg}$ de $\mathrm{MS} / \mathrm{m}^{2}$ ). O uso da casca de arroz resultou em incremento de MS de $241 \%$ em relação ao uso exclusivo do milho como alimento, enquanto o capim-elefante promoveu aumento de apenas $86 \%$, considerando o grão de milho com $84 \%$ de MS. Contudo, em ambos os casos, os valores obtidos superaram o encontrado por Rocha (2004), que avaliou apenas o uso da casca de arroz.

A porcentagem média de $\mathrm{PB}$ da forragem completa, independentemente do tipo de substrato estudado, foi superior a $12 \%$, sendo inferior e superior aos valores divulgados por Oliveira (1998) e Rocha (2004), respectivamente. A importância desse resultado é evidenciada quando se considera o estudo realizado por Zundt et al. (2002) sobre a viabilidade econômica de rações com diferentes níveis de PB. Esses autores constataram que o retorno financeiro é maior quando o teor de PB é igual ou superior a $12 \%$. Outro fator a ser destacado é o estudo de ganho de peso com ovinos realizado por Hussein \& Jordan (1991), que constataram ganhos diários de até $0,25 \mathrm{~kg}$ quando utilizaram rações com $14 \%$ de $\mathrm{PB}$.

Neste estudo, observou-se influência do tipo de substrato $(\mathrm{P}<0,01)$ sobre a porcentagem de $\mathrm{PB}$, verificando-se superioridade do capim-elefante em relação à casca de arroz tanto nas amostras de forragem completa como nas de substrato + raízes, porém, o mesmo não ocorreu quando analisada apenas a parte aérea das plantas. Como constatado também por Amorim et al. (2000), esse resultado caracterizou bem a influência do substrato utilizado sobre a contribuição da parte aérea no teor de PB da forragem.

$\mathrm{Na}$ amostra de substrato + raízes, no tratamento com casca do arroz, o teor de PB foi de apenas 7,59\%, o que, segundo Milford \& Raidock (1965), evidencia comprometimento da qualidade do volumoso, pois os ruminantes necessitam de dietas com pelo menos 7 a $8 \%$ de PB para que possam apresentar níveis de consumo e digestibilidade suficientes para mantença.

O substrato de capim-elefante, comparativamente à palha de arroz, favoreceu a retenção de nitrogênio, pois proporcionou maior teor de PB na amostra substrato + raízes, o que não ocorreu nas amostras da parte aérea das plantas. Com uso da palha de arroz, pode ter ocorrido perda do nitrogênio adicionado via solução nutritiva, provavelmente pela lixiviação, visto que o capim-elefante mostrou-se com maior poder de retenção de umidade durante as irrigações. 
Tabela 1 - Forragem natural $\left(\mathrm{kg} / \mathrm{m}^{2}\right)$, porcentagem de MS total e teores de PB, FDN, FDA e cinzas na MS da forragem de milho hidropônico Table 1 - Fresh forage ( $\left.\mathrm{kg} / \mathrm{n}^{2}\right)$ and percentage of $D M, C P, N D F, A D F$ and ash (DM basis) on hydroponic corn forage

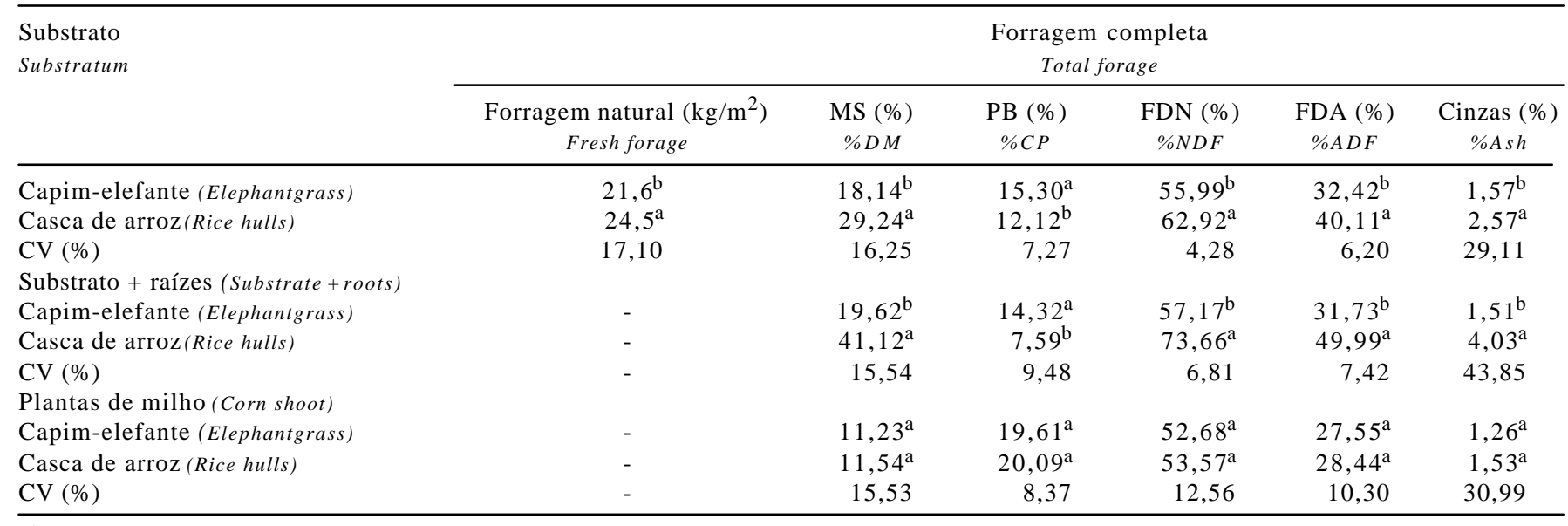

a,b Médias seguidas de letras diferentes na mesma coluna, em cada tipo de amostra, diferem $(P<0,01)$ pelo teste Tukey.

a,b Means, within a column, followed by different letters are different $(P<0.01)$ by Tukey test

Rocha (2004) atribuiu esse efeito ao baixo teor de PB obtido com o uso de casca de arroz, como substrato, e à percolação, face à declividade do canteiro.

A forragem de milho hidropônico possui efeito equivalente ao uso da amonização, pois tem o mesmo princípio enriquecimento de volumosos de baixa qualidade nutricional para ruminantes - e pode ser uma alternativa de complemento a planos de alimentação, mais especificamente em secas mais prolongadas. Entretanto, sua relevância em comparação a outras opções, como as forrageiras nativas, o feno, a silagem e os resíduos da agroindústria, deve-se aos aspectos econômicos e à simplicidade de produção.

A porcentagem de PB foi inferior ao valor de $23,6 \%$ obtido por Souza \& Espíndola (1999), no feno de leucena, sendo superior, no entanto, aos obtidos por Camurça et al. (2002), nos fenos de capim-elefante $(6,68 \%)$ e capim-bufel $(9,03 \%)$, destacando-se também em relação aos encontrados por Wanderley et al. (2002) e Andrade et al. (2002), na palma forrageira (4 a 6\%). Foi superior ainda aos valores descritos por Neumann et al. (2002), de 7,62\% em silagem de sorgo, e por Reis et al. (2001), de 10,2 e 6,9\% para silagens de milho úmido e de milho hidratado, respectivamente. Com uso de amonização, aumentos no teor de proteína bruta têm apresentado grandes variações (Pires et al., 1999). No caso do milho hidropônico, essa variação também ocorre, sendo maior quando ocorre ou não a lavagem da forragem para remoção de sais, o que nãofoi constatado nes ta pesquisa.

Outro aspecto importante na avaliação da forragem de milho hidropônico inclui o teor de MS e seus componentes, que são a porcentagem de FDN, FDA e cinzas (Tabela 1). À semelhança do observado para a PB, não houve influência significativa dos substratos quando avaliada apenas amostra da parte aérea das plantas de milho, o que difere dos resultados reportados por Amorim et al. (2000). Esses autores, no entanto, não fizeram referência ao uso de fertilização e justificaram a superioridade da cama de frango como substrato por disponibilizar mais nutrientes para as plantas. Nesta pesquisa, ao considerar a forragem completa e a amostra do substrato + raízes, constatou-se diferença significativa $(\mathrm{P}<0,01)$ entre os substratos, com maiores valores para a casca de arroz em todas as características.

Quanto ao maior teor de MS quando utilizada a casca de arroz como substrato, deve-se ressaltar que o valor de $73,66 \%$ para FDN da amostra substrato + raízes e o elevado teor de cinzas constituem-se indícios de que a qualidade nutricional dessa MS pode ser questionável, pois a casca do arroz possui alto teor de silício (90\% nas cinzas), como constatado por Della et al. (2001). Além disso, esse elemento ser considerado importante inibidor de digestão da fibra em volumosos (Paiva et al., 1995).

Observou-se que a MS do milho hidropônico foi inferior à de materiais tratados com amônia ou uréia (Sarmento et al., 1999; Sousa Gesualdi et al., 2001) e superior à da palma forrageira (Andrade et al., 2002; Wanderley et al., 2002), que variou de 10 a $14 \%$, com 26,8\% de FDN. Segundo Guim et al. (2002), o baixo teor de MS é fator limitante também para o uso do capim-elefante em forma de silagem. Esses autores recomendaram o uso do emurchecimento para contornar essa limitação.

Quanto aos aspectos desfavoráveis, pode ocorrer incidência de lagarta-do-milho (Laphygma frugiperda), como constataram Amorim et al. (2000), e proliferação de fungos nos locais com excesso de umidade, pois há tendência de formação de bolores quando o milho hidropônico é cultiva do 
Tabela 2 - Correlações entre os teores de MS, PB, FDN, FDA e cinzas na MS da forragem de milho hidropônico

Table 2 - Correlation between CP, DM, FDN, FDA and ash in DM hydroponic corn forage

\begin{tabular}{lrrrr}
\hline & PB & FDN & FDA & \multicolumn{1}{c}{ Cinzas } \\
& $C P$ & $N D F$ & $A D F$ & \multicolumn{1}{c}{ Ash } \\
\hline MS $(D M)$ & $-0,94$ & 0,79 & 0,93 & 0,86 \\
PB $(C P)$ & 1 & $-0,75$ & $-0,90$ & $-0,77$ \\
FDN $(N D F)$ & & 1 & 0,83 & 0,63 \\
FDA $(A D F)$ & & & 1 & 0,84 \\
Cinzas $(A s h)$ & & & & 1 \\
\hline
\end{tabular}

em substrato de capim-elefante. Com o uso da casca de arroz, no entanto, isso não ocorreu.

Na Tabela 2 são apresentadas as correlações entre os teores de MS total, PB, FDN, FDA e cinzas. Merece, no entanto, mais atenção a constatação de correlação negativa da PB com os componentes da MS, FDN, FDA e cinzas, bem como a qualidade da fibra, que são bons indicadores da qualidade da forragem. Cabral et al. (2002) relataram que são numerosos os estudos demonstrando a relação inversa entre FDN e consumo de MS e entre FDA e digestibilidade aparente.

Os resultados de correlação negativa da $\mathrm{PB}$ com os demais componentes da MS total evidenciam que a MS total é predominantemente formada por fibras e sílica, que, por sua vez, estão relacionadas à redução da qualidade da forragem. Neste estudo, provavelmente essa redução de qualidade esteja associada à maior participação da casca de arroz, haja vista a maior contribuição na MS total, tanto na forragem completa como na amostra do substrato + raízes.

Os valores mais elevados de FDN e FDA quando usada a casca de arroz como substrato (Tabela 1) indicam predomínio de fibras de difícil digestão, como lignina e celulose nesse substrato, o que também foi evidenciado pelas correlações constatadas entre FDN e FDA e a MS total.

\section{Agradecimento}

À NORAGRO Produtos Agrícola, pelo apoio financeiro à realização da pesquisa.

\section{Conclusões}

O uso de casca de arroz, em comparação ao de capimelefante picado, como substrato no cultivo de milho hidropônico resultou em forragem de menor qualidade, por elevar os teores de fibra e cinzas.

O baixo teor de MS apresentou-se como fator desfavorável do uso do capim-elefante picado como substrato para produção do milho hidropônico.

\section{Literatura Citada}

AMORIM, A.C.; RESENDE, K.T.; MEDEIROS, A.N. et al. Produção de milho (Zeamays) para forragem, através de sistema hidropônico. In: REUNIÃO ANUAL DA SOCIEDADE BRASILEIRA DE ZOOTECNIA, 38., 2000, Viçosa, MG. Anais... Viçosa, MG: Sociedade Brasileira de Zootecnia/Gmosis, [2000]. (CD-ROM).

ANDRADE, D.K.B.; FERREIRA, M.A.; VÉRAS, A.S.C. et al. Digestibilidade e absorção aparente em vacas da raça holandesa alimentadas com palma forrageira (Opuntia ficus-indica Mill) em substituição à silagem de sorgo (Sorgum bicolor (L) Moench). Revista Brasileira de Zootecnia, v.31, n.5, p.2088-2097, 2002.

CABRAL, L.S.; VALADARES FILHO, S.C.; DETMANN, E. et al. Cinética ruminal das frações de carboidratos, produção de gás, digestibilidade in vitro da matéria seca e NDT estimado da silagem de milho com diferentes proporções de grãos. Revista Brasileira de Zootecnia, v.31, n.6, p.2332-2339, 2002.

CAMURÇA, D.A.; NEIVA, J.N.M.; PIMENTEL, J.C.M. et al. Desempenho produtivo de ovinos alimentados com dietas a base de fenos de gramíneas tropicais. Revista Brasileira de Zootecnia, v.31, n.5, p.2113-2122, 2002.

DELLA, V.P.; KUHN, I.; HOTZA, D. Caracterização de cinzas da casca de arroz e uso como matéria prima na fabricação de refratários de sílica. Química Nova, v.24, p.778-782, 2001.

EUCLYDES, R.F. Manual de utilização do programa SAEG (Sistema de Análise Estatística e Genética). Viçosa, MG: Universidade Federal de Viçosa, 1983. 59p.

GUIM, A.; ANDRADE, P.; ITURRINO-SCHOCKEN, R.P. et al. Estabilidade aeróbica de silagem de capim elefante (Penninsetum purpureum, Schum) emurchecido e tratado com inoculante microbiano. Revista Brasileira de Zootecnia, v.31, n.6, p. 2176-2485, 2002 .

HUSSEIN, H.S.; JORDAN, R.M. Fish meal as a protein supplement in finishing lamb diets. Journal of Animal Science, v.69, p.2115-2122, 1991

MILFORD, R.; RAIDOCK, K.P. The nutrient value of protein in subtropical pasture species grown in southeast Queensland. Australian Journal Experimental Agriculture Animal Husbandry, v.5, p.13-17, 1965.

NEUMANN, M.; RESTLÉ, J.; ALVES FILHO, D.C. et al. Avaliação do valor nutritivo da planta e da silagem de diferentes híbridos de sorgo (Sorghum bicolor, L. Moench). Revista Brasileira de Zootecnia, v.31, n.1, p.293-301, 2002 (supl.).

OLIVEIRA, A.C.L. Forragem hidropônica de milho: alternativa para o desenvolvimento sustentável do agente produtivo. Fortaleza: Banco do Nordeste, 1998. 18p. (apostila).

PAIVA, J.A.J.; GARCIA, R.; QUEIROZ, A.C. et al. Efeitos dos níveis de amônia anidra e períodos de amonização sobre os teores dos constituintes da parede celular na palhada de milho. Revista Brasileira de Zootecnia, v.24, n.5, p.683-691, 1995

PIRES, A.J.V.; GARCIA, R.; CECON, P.R. et al. Amonização da quirera de milho com alta umidade. Revista Brasileira de Zootecnia, v.28, n.6, p.1186-1193, 1999.

REIS, W.; JOBIM, C.C.; MACEDO, F.A.F. et al. Desempenho de cordeiros terminados em confinamento, consumindo silagem de milho com alta umidade ou grãos de milho hidratados em substituição aos grãos de milho seco da dieta. Revista Brasileira de Zootecnia, v.30, n.2, p.596-603, 2001.

ROCHA, R.J.S. Produtividade e composição químicobromatológica da forragem hidropônica de milho (Zea mays L.) em diferentes densidades de plantio, estádios de crescimento e volumes de solução nutritiva. Teresina: Universidade Federal do Piauí, 2004. 48p. Dissertação (Mestrado em Ciência Animal) - Universidade Federal do Piauí, 2004.

SARMENTO, P.; GARCIA, R.; PIRES, A.J.V. et al. Tratamento do bagaço de cana-de-açúcar com uréia. Revista Brasileira de Zootecnia, v.28, n.6, p.1203-1208, 1999. 
SILVA, D.J. Análise de alimentos: métodos químicos e biológicos. Viçosa, MG: Universidade Federal de Viçosa, 1998. 165p.

SOUZA, A.A.; ESPÍNDOLA, G.B. Efeito da suplementação com feno de leucena (Leucaena leucocephala (Lam) de Wit) durante a estação seca sobre o desenvolvimento ponderal de ovinos. Revista Brasileira de Zootecnia, v.28, n.6, p.1424-1429, 1999.

SOUZA GESUALDI, A.C.L.; SILVA, J.F.C.; VASQUEZ, H.M. et al. Efeito da amonização sobre a composição, a retenção de nitrogênio e a conservação do bagaço e da ponta de cana-deaçúcar. Revista Brasileira de Zootecnia, v.30, n.2, p.508$517,2001$.

TEIXEIRA, J.R.C. Efeito da amônia anidra no valor nutritivo da palha de milho mais sabugo e do capim elefante cv. Cameron fornecidos a novilhos Nelore em confinamento. Viçosa, MG: Universidade Federal de Viçosa, 1990. 97p. Dissertação (Mestrado em Zootecnia) - Universidade Federal de Viçosa, 1990.
ZUNDT, M.; MACEDO, F.A.F.; MARTINS, E.N. et al. Desempenho de cordeiros alimentados com diferentes níveis protéicos. Revista Brasileira de Zootecnia, v.31, n.3, p.1307-1314, 2002.

WANDERLEY, W.L.; FERREIRA, M.A.; ANDRADE, D.K.B. et al. Palma forrageira (Opuntia ficus-indica Mipp) em substituição à silagem de sorgo (Sorgum bicolor $(\mathrm{L})$ Moench) na alimentação de vacas leiteiras. Revista Brasileira de Zootecnia, v.31, n.1, p.273-281, 2002. 